\title{
Capacitated Multi-item joint Procurement Models with Outsourcing and
}

\section{Backlogging}

\author{
Jinhong Zhong ${ }^{1, a^{*}}$, Yong Wang ${ }^{2, b}$ and Xiaofei $\mathrm{Yu}^{3, \mathrm{c}}$ \\ ${ }^{1}$ School of management, Hefei University of Technology, Hefei 230009, China \\ ${ }^{2}$ School of management, Hefei University of Technology, Hefei 230009, China \\ ${ }^{3}$ School of management, Hefei University of Technology, Hefei 230009, China

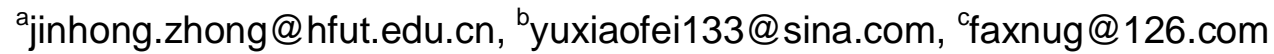

Keywords: Multi-item dynamic lot-sizing problem; Outsourcing; Backlogging; Budget restriction Abstract. This paper addresses a multi-item joint procurement lot-sizing problem with limited budget, outsourcing, and backlogging, where product-dependent minor setup cost and major setup cost are considered. We build four models and code Lingo-based simulation scripts. By the comparative experiments, we find that backlogging and outsourcing policies can reduce the system total cost.

\section{Introduction}

Economic globalization results in the more complex and changeable customer demand, and the finer division of labor and the wider cooperation among the enterprises. Therefore, the enterprises can provide customers with better products and services only through their closer cooperation. Outsourcing policy can reduce costs while improve quality of service and customer satisfaction, has become a usual tool to meet the customers requirement with more variability. The dealer engaging in a variety of goods often faces the multi-item joint procurement problem under limited purchasing budget. When outsourcing is taken into account, customer demand can be satisfied not only by procurement, and/or through inventory from previous periods, and/or by backlogging from subsequent periods, but also it can be partially or entirely outsourced. The problem can be modeled as multi-item dynamic lot-sizing problem (MDLSP) with outsourcing and backlogging, the optimization objective is to minimize the total cost.

The multi-item dynamic lot-sizing problem is the extension of the classic work of Wagner and Whitin (1958). HINDI (1995) researches the single-level MDLSP with single capacitated resource, develops a solution strategy based on a branch-and-bound search, whereby column generation algorithm is employed to solve a linear programming relaxation of the model based on variable redefinition, the resulting subproblems are then single-item uncapacitated lot-sizing problems solved as shortest path problems, effective good upper bounds are also generated by solving an appropriate minimum-cost network flow problem at each node of the branch-and-bound tree. Bylka and Rempala (2001) research the MDLSP with nonlinear production cost and linear holding cost, the total cost is obtained by an auxiliary allocation approach. Minner (2009) researches the MDLSP with limited warehouse capacity, and then suggests a saving-based heuristic which is compared with constructive approach according to cost-based priority rule and smoothing heuristic. Gicquel et al. (2009) research the discrete lot-sizing and scheduling problem with sequence-dependent changeover costs, propose a new way of modeling the production system based on the use of a multi-attribute product structure, where products can be identified not only by a unique index, but 
also a set of physical attributes such as color, they show that it can reduce the size of the model due to looking at changeovers at an aggregate level using the relevant physical attributes instead of considering each individual changeover between items. For the MDLSP with transportation, Lee et al. (2005) consider the case of the fixed capacity of transportation container, and devise a heuristic with an adjustment mechanism according to the optimal solution properties. Sancak and SibelSalman (2011) address the multi-period problem by considering safety stock and the option of delaying a less-than-full truckload shipment to the next period, analyze the impact of delaying shipments on both cost and service levels. For the MDLSP with supplier selection, Basnet and Leung (2005) consider supplier-dependent transaction cost, product-dependent holding cost and purchasing cost depended on both supplier and product, present an enumerative search algorithm and a heuristic. Rezaei and Davoodi (2011) establish multi-objective non-linear programming model respectively for the loss sales case and backlogging case, where the optimal objectives are comprised of total cost, total quality level and total service level, employ NSGA-II algorithm to solve them.

In the literature on MDLSP, there exist some works considering setup time and setup cost. Caserta and Quiñonez Rico (2009) research the multi-period capacitated MDLSP with setup time, propose a hybrid algorithm based on cross entropy and Lagrangean relaxation. Brahimi et al. (2010) investigate the capacitated MDLSP with non-customer specific production time windows and setup times, which is resolved respectively by a Lagrangean relaxation-based heuristic and by a commercial software on new reformulations. Muller et al. (2012) address the capacitated MDLSP with setup times, and present a hybrid heuristic solution approach based on the adaptive large neighborhood search heuristic framework where a mixed integer programming solver is used to improve solutions. Chan and Chiu (1997) research the MDLSP with major setup cost and minor setup cost, develop an extension of the one-way-eyeballing-heuristic to a multi-product algorithm. Pratsini (2000) analyzes the effect of decreasing setups through learning on the capacitated MDLSP where setup cost is involved in the objective function and setup time is considered in the capacity constraint, and develop a heuristic to solve the model. Narayanan and Robinson (2010) researched the joint procurement decision problem for a family of products that share a constrained resource such as an ocean shipping container, where major setup cost and minor setup cost are taken into account, then proposed a six-phase heuristic and simulated annealing meta-heuristic.

There are some contributions concentrating on the DLS problem with outsourcing, such as lost sales model (Aksen et al. 2003, Sandbothe and Thompson 1990), outsourcing model (Chu and Chu 2007), subcontract model (Atamtürk and Hochbaum 2001), mutli-mode transportation model (Jaruphongsa et al. 2005), multi-location inventory model with dynamic transshipment (Herer and Tzur 2001), and so on. Here we merely review the studies on MDLSP with outsourcing. Van Norden and van de Velde (2005) research the MDLSP with reserved and additional transportation capacity, where the former can be used in exchange for a guaranteed price while the use of the later needs to pay higher prevailing price, they present a Lagrangean relaxation algorithm to compute lower and upper bounds of the problem. Li et al. (2007) research the capacitated MDLSP with substitution, remanufacturing and emergency procurement/ outsourcing, propose a heuristic GA to solve it. Feng et al. (2011) research a supplier selection problem in multi-service outsourcing, build a multi-objective 0-1 programming model involving three objectives, service outsourcing, service waiting time and collaborative utility, develop a multi-objective algorithm based on Tabu search. Lu and Qi (2011) research a MDLSP with lost sales, where each batch will generate the same number of "unit" of all products, develop a polynomial time algorithm for the case without lost sales, and two heuristic algorithms for the case with lost sales. Absi and Kedad-Sidhoum (2008) consider a 
capacitated MDLSP with setup times and shortage costs, and develop a branch-and-cut framework to find near optimal solutions which involves strong valid inequlities derived from the single period relaxation of the problem. Later, Absi and Kedad-Sidhoum(2009) extend their own work by considering safety stock, present a Lagrangian relaxation of the capacity constraints to obtain lower and upper bounds for the problem where the induced sub-problems are solved through a dynamic programming algorithm developed by them. More recently, Absi et al.(2013) propose a novel Lagrangian relaxation algorithm for the same problem as Absi and Kedad-Sidhoum (2008), where each subproblem is solved using an adaptation of the dynamic programming algorithm of Aksen et al.(2003), and feasible solutions are found by employing a non-myopic heuristic based on a probing strategy and a refining procedure. Moreover, they also propose a metaheuristic based on the adaptive large neighborhood search principle to improve solutions. Jolayemi and Olorunniwo (2004) establish a mixed integer linear programming model for the production and transportation planning problem in multi-plant and multi-warehouse environment with extensible capacities, where the shortfalls can be satisfied through subcontracting or the use of inventory if production cannot met demand, they also develop a procedure for reducing the model's size which will enhance the applicability of the model. Sambasivan and Yahya (2005) develop Lagrangian relaxation algorithm for the capacitated MDLSP with inter-plant transfers. Nascimento et al. (2010) develop a greedy randomized adaptive search procedure heuristic as well as a path-relinking intensification procedure to find cost-effective solutions for the same problem.

The rest of the paper is outlined as follows. Section 2 gives the mathematical formulations of the four models under study. Section 3 presents Lingo-based simulation experiments. Section 4 concludes this study.

\section{Problem Models}

We research the multi-item joint procurement problem with the product-dependent minor setup cost and major setup cost. Product demands in each period are assumed to be dynamic, and can be acquired using the customer orders and demand forecasting. Demands can be met by the combination of purchasing, inventory on hand, backlogging and outsourcing policy. Suppose that there is no replenishment lead time as in many DLS papers. The total budget purchasing products in each period is limited. The problem is that of satisfying all demands in the planning horizon at minimal total cost. To describe the model, the following notations are defined:

$T \quad$ length of the planning horizon

$t \quad$ time period $(t=1, \ldots, T)$

$N$ number of products

$i \quad$ product index $(i=1, \ldots, N)$

$d_{i t} \quad$ demand of product $i$ in period $t$

$S_{t} \quad$ major setup cost at period $t$

$K_{i t} \quad$ minor setup cost of product $i$ in period $t$

$P_{i t} \quad$ unit procurement cost of product $i$ in period $t$

$H_{i t} \quad$ unit holding cost of product $i$ in period $t$

$R_{i t} \quad$ unit outsourcing cost of product $i$ in period $t$

$G_{i t}$ unit backlogging cost of product $i$ in period $t$

$C_{t} \quad$ procurement budget at period $t$

$M \quad$ an arbitrarily large number

The decision variables:

$X_{i t}$ procurement level of product $i$ in period $t$ 
$L_{i t} \quad$ outsourcing level of product $i$ in period $t$

$B_{i t} \quad$ backlogging level of product $i$ in period $t$

$I_{i t} \quad$ inventory level of product $i$ at the end of period $t$

$Y_{i t} \quad$ a binary variable indicating whether product $i$ in period $t$ is procured, i.e. $Y_{i t}=1$ if $X_{i t}>0$, otherwise $Y_{i t}=0$

$Z_{t} \quad$ a binary variable indicating whether period $t$ is a procurement period, i.e. $Z_{t}=1$ if $\sum_{i=1}^{N} X_{i t}>0$, otherwise $Z_{t}=0$

The capacitated multi-item joint procurement model with outsourcing and backlogging can be formulated as follows:

$$
\begin{array}{rc}
\operatorname{Min}\left\{\sum_{i=1}^{N} \sum_{t=1}^{T}\left(K_{i t} Y_{i t}+P_{i t} X_{i t}+H_{i t} I_{i t}+R_{i t} L_{i t}+G_{i t} B_{i t}\right)+\sum_{t=1}^{T} S_{t} Z_{t}\right\} \\
\text { s.t. } \quad I_{i t}=I_{i t-1}+X_{i t}+L_{i t}+B_{i t}-B_{i t-1}-d_{i t} & i=1, \ldots, N, t=1, \ldots, T \\
S_{t} Z_{t}+\sum_{i t=1}^{N}\left(X_{i t} P_{i t}+K_{i t} Y_{i t}\right) \leq C_{t} Z_{t} & i=1, \ldots, N, t=1, \ldots, T \\
X_{i t} \leq M Y_{i t} & i=1, \ldots, T \\
Y_{i t} \leq Z_{t} & i=1, \ldots, N, t=1, \ldots, T \\
Y_{i t} \in\{0,1\}, Z_{t} \in\{0,1\} & i=1, \ldots, N, t=1, \ldots, T \\
I_{i 0}=I_{i T}=0 & i=1, \ldots, N \\
B_{i o}=B_{i t}=0 & i=1, \ldots, N \\
X_{i t} \geq 0, L_{i t} \geq 0, I_{i t} \geq 0, B_{i t} \geq 0 & i=1, \ldots, N, t=1, \ldots, T
\end{array}
$$

The objective function (1) seeks to minimize the total costs, which includes the procurement, holding, backlogging and outsourcing costs. Constraints (2) are the material balance equation. Constraints (3) show that outsourcing level of per product at each period should not exceed its current demand. Constraints (4) are the funds constraints. Constraints (5) force $Y_{i t}$ to one when $X_{i t}$ is positive. Constraints (6) prevent an item setup from occurring unless the product family is setup. Constraints (7) define $Y_{i t}$ and $Z_{t}$ as binary values. Constraints (8) and (9) mean that both inventory level and backlogging level at periods 0 and $T$ are zero. Constraints (10) mean procurement, outsourcing, holding and backlogging levels are non-negative integers.

To verify the influence of outsourcing and backlogging policies on the model performance, we also build the following three models: (i) the model with outsourcing (P2), which can be obtained by removing the items and constraints associated with backlogging from the (P1). (ii) the model with backlogging (P3), which has no items and constraints relative to outsourcing compared to (P1). (iii) the model without outsourcing and backlogging (P4), which doesn't comprise the items and constraints relevant to outsourcing and backlogging in (P1). 


\section{Simulation Experiment}

We employ LINGO 11 to solve the four models. By comparing their results, we find out that outsourcing and/or backlogging can significantly improve the system performance.

We consider the dynamic seasonal demand, which can be formulated as,

$$
d_{i t}=200+67 \varepsilon_{i t}+125 \sin [(\pi(t+3)) / 6] \quad i=1, \ldots, N, t=1, \ldots, T
$$

where $\varepsilon_{i t}$ is standard normal distribution.

In the experiment, we set $T=12, N=2, M=10000$. The other model parameters are yielded randomly by uniform distribution defined on the interval $(A, B)$ as shown in table 1 .

Table 1 parameters settings of the model

\begin{tabular}{cl}
\hline parameter & \multicolumn{1}{c}{ setting } \\
\hline procurement budget $C_{t}$ & $(6000,7000)$ \\
Major setup cost $S_{t}$ & 100 \\
Minor setup cost $K_{i t}$ & $(40,70)$ \\
unit procurement $\operatorname{cost} P_{i t}$ & $(5,10)$ \\
unit holding cost $H_{i t}$ & $(0.5,1.5)$ \\
unit outsourcing $\operatorname{cost} R_{i t}$ & $(7,11)$ \\
unit backlogging $\operatorname{cost} G_{i t}$ & $(0.5,1.5)$ \\
\hline
\end{tabular}

Table 2 shows an instance generated randomly by LINGO. By means of LINGO solver, we can obtain the results of four models which are shown in Table 3 and Table 4.

Table 2 a problem instance

\begin{tabular}{ccccccccccccc}
\hline$t$ & 1 & 2 & 3 & 4 & 5 & 6 & 7 & 8 & 9 & 10 & 11 & 12 \\
\hline$C_{t}$ & 6534 & 6979 & 6483 & 6890 & 6583 & 6632 & 6155 & 6691 & 6467 & 6608 & 6040 & 6554 \\
$d_{1 t}$ & 338 & 347 & 186 & 129 & 185 & 8 & 143 & 130 & 171 & 148 & 379 & 458 \\
$d_{2 t}$ & 314 & 399 & 197 & 220 & 106 & 97 & 23 & 170 & 194 & 280 & 191 & 334 \\
$S_{t}$ & 100 & 100 & 100 & 100 & 100 & 100 & 100 & 100 & 100 & 100 & 100 & 100
\end{tabular}

$K_{1 t} 60.189466 .950652 .548853 .577967 .573444 .846463 .384653 .770650 .111241 .347065 .744869 .2968$

$K_{2 t} 56.037969 .390154 .509866 .715657 .514758 .969344 .676960 .754154 .022258 .269441 .224756 .6396$

$\begin{array}{lllllllllllll}P_{1 t} & 8.3649 & 9.4918 & 7.0915 & 7.2630 & 9.5956 & 5.8077 & 8.8974 & 7.2951 & 6.6852 & 5.2245 & 9.2908 & 9.8828\end{array}$

$\begin{array}{llllllllllllll}P_{2 t} & 7.6730 & 9.8984 & 7.4183 & 9.4526 & 7.9191 & 8.1615 & 5.7795 & 8.4590 & 7.3370 & 8.0449 & 5.2041 & 7.7733\end{array}$

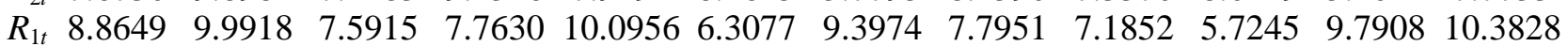

$\begin{array}{lllllllllllll}R_{2 t} & 8.1730 & 10.3984 & 7.9183 & 9.9526 & 8.4191 & 8.6615 & 6.2795 & 8.9590 & 7.8370 & 8.5449 & 5.7041 & 8.2733\end{array}$

$\begin{array}{lllllllllllll}G_{1 t} & 1.1730 & 1.3984 & 0.9183 & 0.9526 & 1.4191 & 0.6615 & 1.2795 & 0.9590 & 0.8370 & 0.5449 & 1.3582 & 1.4766\end{array}$

$\begin{array}{lllllllllllll}G_{2 t} & 1.0346 & 1.4797 & 0.9837 & 1.3905 & 1.0838 & 1.1323 & 0.6559 & 1.1918 & 0.9674 & 1.1090 & 0.5408 & 1.0547\end{array}$

$\begin{array}{lllllllllllll}H_{1 t} & 1.1730 & 1.3984 & 0.9183 & 0.9526 & 1.4191 & 0.6615 & 1.2795 & 0.9590 & 0.8370 & 0.5449 & 1.3582 & 1.4766\end{array}$

\begin{tabular}{lllllllllllll}
$H_{2 t}$ & 1.0346 & 1.4797 & 0.9837 & 1.3905 & 1.0838 & 1.1323 & 0.6559 & 1.1918 & 0.9674 & 1.1090 & 0.5408 & 1.0547 \\
\hline
\end{tabular}

Table 3 system costs at optimality

\begin{tabular}{lllll}
\hline & Total holding cost & Total backlogging cost & Total outsourcing cost & System overall cost \\
\hline P1 & 2094.08 & 4927.82 & 2182.43 & 37776.72 \\
P2 & 2881.09 & 0 & 7017.16 & 39671.70 \\
P3 & 1707.92 & 3385.73 & 0 & 38130.15 \\
P4 & 2525.55 & 0 & 0 & 40070.41 \\
\hline
\end{tabular}


Table 4 optimal policies for the four models

\begin{tabular}{cccccccccccccc}
\hline & $t$ & 1 & 2 & 3 & 4 & 5 & 6 & 7 & 8 & 9 & 10 & 11 & 12 \\
\hline \multirow{4}{*}{$\mathbf{P 4}$} & $\boldsymbol{X}_{1 t}$ & 338 & 347 & 186 & 314 & 0 & 281 & 0 & 0 & 171 & 985 & 0 & 0 \\
& $\boldsymbol{S}_{1 t}$ & 0 & 0 & 0 & 185 & 0 & 273 & 130 & 0 & 0 & 837 & 458 & 0 \\
& $\boldsymbol{X}_{2 t}$ & 454 & 259 & 417 & 0 & 106 & 97 & 193 & 0 & 474 & 0 & 525 & 0 \\
& $\boldsymbol{S}_{2 t}$ & 140 & 0 & 220 & 0 & 0 & 0 & 170 & 0 & 280 & 0 & 334 & 0 \\
\hline \multirow{4}{*}{} & $\boldsymbol{X}_{1 t}$ & 336 & 0 & 411 & 253 & 0 & 385 & 0 & 0 & 0 & 1237 & 0 & 0 \\
& $\boldsymbol{B}_{1 t}$ & 2 & 349 & 124 & 0 & 185 & 0 & 0 & 81 & 252 & 0 & 0 & 0 \\
$\mathbf{P 3}$ & $\boldsymbol{S}_{1 t}$ & 0 & 0 & 0 & 0 & 0 & 192 & 49 & 0 & 0 & 837 & 458 & 0 \\
& $\boldsymbol{X}_{2 t}$ & 457 & 0 & 453 & 0 & 0 & 0 & 616 & 0 & 0 & 0 & 999 & 0 \\
& $\boldsymbol{B}_{2 t}$ & 0 & 256 & 0 & 220 & 326 & 423 & 0 & 0 & 194 & 474 & 0 & 0 \\
& $\boldsymbol{S}_{2 t}$ & 143 & 0 & 0 & 0 & 0 & 0 & 170 & 0 & 0 & 0 & 334 & 0 \\
\hline \multirow{4}{*}{} & $\boldsymbol{X}_{1 t}$ & 0 & 347 & 186 & 314 & 0 & 281 & 0 & 0 & 0 & 985 & 0 & 0 \\
& $\boldsymbol{L}_{1 t}$ & 338 & 0 & 0 & 0 & 0 & 0 & 0 & 0 & 171 & 0 & 0 & 0 \\
$\mathbf{P 2}$ & $\boldsymbol{S}_{1 t}$ & 0 & 0 & 0 & 185 & 0 & 273 & 130 & 0 & 0 & 837 & 458 & 0 \\
& $\boldsymbol{X}_{2 t}$ & 713 & 0 & 417 & 0 & 0 & 0 & 387 & 0 & 0 & 156 & 525 & 0 \\
& $\boldsymbol{L}_{2 t}$ & 0 & 0 & 0 & 0 & 106 & 97 & 0 & 0 & 0 & 124 & 0 & 0 \\
& $\boldsymbol{S}_{2 t}$ & 399 & 0 & 220 & 0 & 0 & 0 & 364 & 194 & 0 & 0 & 334 & 0 \\
\hline & $\boldsymbol{X}_{1 t}$ & 0 & 0 & 533 & 0 & 0 & 336 & 0 & 0 & 0 & 1237 & 0 & 0 \\
& $\boldsymbol{L}_{1 t}$ & 338 & 0 & 0 & 129 & 0 & 0 & 0 & 0 & 0 & 49 & 0 & 0 \\
& $\boldsymbol{B}_{1 t}$ & 0 & 347 & 0 & 0 & 185 & 0 & 0 & 130 & 301 & 0 & 0 & 0 \\
$\mathbf{P 1} 1$ & $\boldsymbol{S}_{1 t}$ & 0 & 0 & 0 & 0 & 0 & 143 & 0 & 0 & 0 & 837 & 458 & 0 \\
& $\boldsymbol{X}_{2 t}$ & 712 & 0 & 336 & 0 & 0 & 0 & 396 & 0 & 0 & 0 & 999 & 0 \\
& $\boldsymbol{L}_{2 t}$ & 1 & 0 & 81 & 0 & 0 & 0 & 0 & 0 & 0 & 0 & 0 & 0 \\
& $\boldsymbol{B}_{2 t}$ & 0 & 0 & 0 & 0 & 106 & 203 & 0 & 0 & 194 & 474 & 0 & 0 \\
& $\boldsymbol{S}_{2 t}$ & 399 & 0 & 220 & 0 & 0 & 0 & 170 & 0 & 0 & 0 & 334 & 0 \\
\hline
\end{tabular}

From Table 3, we can see that outsourcing and backlogging policies are helpful for decreasing the system total cost although they may incur the increasing of some single cost.

From Table 4, we observe that demand is satisfied flexibly due to the introduction of outsourcing and backlogging. For instance, purchasing at a period can satisfy the demand for more than one period (e.g. ), the demand at a period can be met by partial procurement and partial outsourcing (e.g. ), the demand at several periods can be backordered to some subsequent period (e.g. ), purchasing and partial backlogging are used to satisfy the demand all together in view of limited budget (e.g. ), the demand at a period is fully outsourced (e.g. ), and so on. These phenomena can be explained from the perspective of minimal cost according to Table 2.

\section{Conclusions}

This paper reviews the researches on single-level multi-item DLS problem. We research the single-stage multi-item joint procurement problem in the presence of a single capacitated resource, minor setup cost and major setup cost. In order to verify the influence of outsourcing and backlogging policies on the optimal solutions for the problem under study, we establish four models and employ the Lingo solver to solve them for the same problem parameters. By the simulation experiments, we show that outsourcing and/or backlogging policies can lessen the system overall cost. The future work is to design a heuristic algorithm to solve the actual problem with appropriate size.

\section{References}

[1] H.M. Wagner and T.M. Whitin, "Dynamic version of the economic lot-size model," Management Science, Vol. 5, No. 1, 1958, pp. 89-96. 
[2] K.S. HINDI, "Computationally efficient solution of the multi-item, capacitated lot-sizing problem," Computers \& Industrial Engineering, Vol. 28, No. 4, 1995, pp. 709-719.

[3] Stanislaw Bylka and Ryszarda Rempala, "Multi-product inventory and auxiliary allocation problem,” Int. J. Production Economics, Vol.71, 2001, pp. 295-303.

[4] Stefan Minner, "A comparison of simple heuristics for multi-product dynamic demand lot-sizing with limited warehouse capacity," Int. J. Production Economics, Vol. 118, 2009, 305-310.

[5] C. Gicquel, N. Miègeville, M. Minoux and Y. Dallery, "Discrete lotsizing and scheduling using product decomposition into attributes," Computers \& Operations Research, Vol. 36, No. 9, 2009, pp. 2690-2698.

[6] Woon-Seek Lee, Jong-Han Han and Sung-Jin Cho, "A heuristic algorithm for a multi-product dynamic lot-sizing and shipping problem," Int. J. Production Economics,Vol. 98, 2005, pp. 204-214.

[7] Emre Sancak and F. Sibel Salman, "Multi-item dynamic lot-sizing with delayed transportation policy," Int. J. Production Economics, Vol. 131, No. 2, 2011, pp. 595-603.

[8] Chuda Basnet and Janny M.Y. Leung, "Inventory lot-sizing with supplier selection," Computers \& Operations Research, Vol. 32, 2005, pp. 1-14.

[9] Jafar Rezaei and Mansoor Davoodi, "Multi-objective models for lot-sizing with supplier selection,” Int. J. Production Economics, Vol. 130, 2011, pp. 77-86.

[10]M. Caserta and E. Quiñonez Rico, "A cross entropy-Lagrangean hybrid algorithm for the multi-item capacitated lot-sizing problem with setup times," Computers \& Operations Research, Vol. 36, No. 2, 2009, pp. 530 - 548.

[11]Nadjib Brahimi, Stéphane Dauzere-Peres and Laurence A. Wolsey, "Polyhedral and Lagrangian approaches for lot sizing with production time windows and setup times," Computers \& Operations Research, Vol. 37, 2010, pp. $182-188$.

[12]Laurent Flindt Muller, Simon Spoorendonk and David Pisinger, "A hybrid adaptive large neighborhood search heuristic for lot-sizing with setup times," European Journal of Operational Research, Vol. 218, 2012, pp. 614-623.

[13]Gin Hor Chan and Kim Suan Chiu, "A SIMPLE HEURISTIC FOR MULTI-PRODUCT DYNAMIC LOT SIZING PROBLEMS,” Computers Ops Res., Vol. 24, No. 10, 1997, pp. 969-979.

[14]E. Pratsini, "The capacitated dynamic lot size problem with variable technology," Computers \& Industrial Engineering, Vol. 38, 2000, pp. 493-504.

[15] Arunachalam Narayanan and Powell Robinson, "Efficient and effective heuristics for the coordinated capacitated lot-size problem," European Journal of Operational Research, Vol. 203, 2010, pp. 583-592.

[16]Deniz Aksen, Kemal Altinkemer and Suresh Chand, "The single-item lot-sizing problem with immediate lost sales," European Journal of Operational Research, Vol. 147, No. 3, 2003, pp. 558-566.

[17]R.A. Sandbothe and G.L. Thompson, "A forward algorithm for the capacitated lot size model with stockouts," Ops. Res., Vol. 38, No. 3, 1990, pp. 474-486. 
[18]Chu F. and Chu C. "Polynomial algorithms for single item lot sizing models with bounded inventory and backlogging or outsourcing," IEEE Transactions on Automation Science and Engineering, Vol. 4, No. 2, 2007, pp. 233-251.

[19]A. Atamtürk and D.S. Hochbaum, "Capacity acquisition, subcontracting, and lot sizing," Management Science, Vol. 47, No. 8, 2001, pp. 1081-1100.

[20]W. Jaruphongsa, S. Çetinkaya and C.Y. Lee, "A dynamic lot-sizing model with multi-mode replenishments: polynomial algorithms for special cases with dual and multiple modes," IIE Transactions, Vol. 37, No. 5, 2005, pp. 453-467.

[21] Y.T. Herer and M. Tzur, "The dynamic transshipment problem," Naval Research Logistics, Vol. 48, No. 5, 2001, pp. 386- 408.

[22]Linda van Norden and Steel van de Velde, "Multi-product lot-sizing with a transportation capacity reservation contract," European Journal of Operational Research, Vol. 165, No. 1, 2005, pp. $127-138$.

[23] Yongjian Li, Jian Chen, and Xiaoqiang Cai, "Heuristic genetic algorithm for capacitated production planning problems with batch processing and remanufacturing," Int. J. Production Economics, Vol. 105, 2007, pp. 301-317.

[24]Bo Feng, Zhi-Ping Fan and Yanzhi Li, "A decision method for supplier selection in multi-service outsourcing," Int. J. Production Economics, Vol. 132, 2011, pp. 240-250.

[25]Liang Lu and Xiangtong Qi, "Dynamic lot sizing for multiple products with a new joint replenishment model,” European Journal of Operational Research, Vol. 212, 2011, pp. 74-80.

[26]Nabil Absi and Safia Kedad-Sidhoum, "The multi-item capacitated lot-sizing problem with setup times and shortage costs," European Journal of Operational Research, Vol. 185, 2008, pp. 1351-1374.

[27]Nabil Absi and Safia Kedad-Sidhoum. "The multi-item capacitated lot-sizing problem with safety stocks and demand shortage costs," Computers \& Operations Research, Vol. 36, 2009, pp. $2926-2936$.

[28]Nabil Absi, Boris Detienne and Stéphane Dauzère-Pérès, "Heuristics for the multi-item capacitated lot-sizing problem with lost sales," Computers \& Operations Research, Vol. 40, 2013, pp. 264-272.

[29] J.K. Jolayemi and F.O. Olorunniwo, "A deterministic model for planning production quantities in a multi-plant, multi-warehouse environment with extensible capacities," International Journal of Production Economics, Vol. 87, No. 2, 2004, pp. 99-113.

[30] M. Sambasivan and S. Yahya, "A Lagrangean-based heuristic for multi-plant, multi-item, multi-period capacitated lot- sizing problems with inter-plant transfers," Computers \& Operations Research, Vol. 32, No. 3, 2005, pp. 537-555.

[31]Maria C.V. Nascimento, Mauricio G.C. Resende and Franklina M.B. Toledo, "GRASP heuristic with path-relinking for the multi-plant capacitated lot sizing problem," European Journal of Operational Research, Vol. 200, 2010, pp. 747-754. 